\title{
Favorable Life-Style Modification and Attenuation of Cardiovascular Risk Factors
}

\author{
Ryuichi Yamamoto, MD; Takashi Kawamura, MD*; \\ Kenji Wakai, MD*; Yoshio Ichihara, MD**; Takafumi Anno, MD**; \\ Yoshiko Mizuno, MD**; Masashi Yokoi, MD**; Toshiki Ohta, MD***; \\ Akihisa Iguchi, MD; Yoshiyuki Ohno, MD*
}

\begin{abstract}
In order to develop an effective counseling system for prevention of cardiovascular diseases, the association of a favorably changed life-style with improved risk factors was examined. Participants were 7,321 office workers aged 30-69 years from in and around Nagoya city. The age-adjusted odds ratio (OR) and its 95\% confidence interval (CI) were calculated to assess the likelihood of risk factor improvement by favorable life-style modifications during a 3-year period. Those who began to eat breakfast and increased their vegetable intake normalized their previously abnormal diastolic blood pressure with more than twice the likelihood (adjusted OR [95\% CI] 2.89 [1.29-6.46] and 2.60 [1.18-5.75], respectively). 'Began to eat breakfast' was also significantly associated with normalized total cholesterol (TC) $(1.84,[1.05-3.21])$. 'Stopped eating till full' significantly normalized the body mass index $(2.03 ;[1.25-3.28])$, uric acid $(1.65 ;[1.07-2.52])$ and TC $(1.43 ;[1.04-1.97])$. Those who started regular exercise significantly normalized their high-density lipoprotein-cholesterol (HDL-C) abnormality with 1.69-times the likelihood (1.69; [1.24-2.29]) and those who began to walk briskly also improved their TC abnormality (1.85; [1.19-2.89]). HDL-C was normalized with 2.55-times the likelihood in those who quit smoking (2.55; [1.68-3.86]). Because favorable life-style modifications can attenuate abnormal cardiovascular risk factors, then proper advice on specific risk factors should be routinely given at each health check-up in order to prevent the onset of cardiovascular diseases in subsequent years. (Jpn Circ J 1999; 63: 184-188)
\end{abstract}

Key Words: Breakfast; Cardiovascular risk-factors; Exercise; Life-style modification; Walking

$\mathbf{N}$

umerous epidemiological studies have shown that poor life-styles are associated with an increased risk of cardiovascular diseases (CVD), and the incidence of these could be decreased by life-style modification, probably through beneficial effects on the risk factors ${ }^{2-5}$ It is, however, still controversial which life-style specifically affects which risk factors. In order to obtain useful information for establishing an effective counseling system for the prevention of CVD, we examined the association of a favorably changed life-style with improved risk factors, using data obtained from periodic health check-ups for the middle-aged male population.

\section{Methods}

\section{Study Population}

A total of 7,321 men aged 30-69 years participated in multiphase health testing in 1989 and 1992 at Aichi Prefectural Center of Health Care (Nagoya, Japan). Most participants were office workers from in and around Nagoya city, who had to undergo an annual medical checkup in accordance with the Industrial Health and Safety

(Received August 19, 1998; revised manuscript received November 19, 1998; accepted November 27, 1998)

Departments of Geriatrics and *Preventive Medicine, Nagoya University School of Medicine, Nagoya, **Aichi Prefectural Center of Health Care, Nagoya and $* * *$ National Institute of Health and Nutrition, Tokyo, Japan

Mailing address: Ryuichi Yamamoto, MD, 65 Tsuruma-cho, Showaku, Nagoya-city 466-8560, Japan. E-mail: yamamotr@tsuru.med. nagoya-u.ac.jp
Law6 At the Center, each participant routinely underwent a set of laboratory screenings, and was given medical advice according to his test results.

\section{Questionnaire on Life-Style}

Together with the medical check-up, life-style profiles were collected by a self-administered questionnaire with answers in a dichotomized form, which included dietary habits (skip breakfast/not, eat much vegetables/not, eat till full/not, prefer oily food/not, and prefer salty food/not), physical activities (exercise regularly/not, walk briskly/not), and smoking and drinking habits (smoke cigarettes/not and drink alcoholic beverages regularly or occasionally/not). Public health nurses interviewed the participants when the questionnaire was not completely filled out. The validity of this questionnaire has been recently confirmed (unpublished data).

\section{Laboratory Procedures}

Blood pressure was automatically measured with an automatic mercury sphygmomanometer in a supine position after about a 2-min rest. Systolic and diastolic blood pressures were expressed as the level of Swan's first and fifth point, respectively. Body mass index (BMI) was defined as weight $(\mathrm{kg})$ divided by height $(\mathrm{m})$ squared. Venous blood sampled from fasting participants was immediately analyzed for total serum cholesterol, glucose, triglyceride, and uric acid by the in-house chemical autoanalyzer. Participants were asked not to take any drugs for at least $14 \mathrm{~h}$ before blood sampling, but there was no information about medication on the questionnaire. 
Table 1 Frequency of Unfavorable Lift Style and Abnormal Biological Markers in 1989 and Their Improvement Through 1992 Among 7,321 Male Participants of the Comprehensive Health Check at Aichi Prefectural Center of Health Case

\begin{tabular}{|c|c|c|c|}
\hline & & No. of prevalence in $1989(\%)$ & No. of lmprovement through 1992 (\%) \\
\hline \multicolumn{4}{|l|}{ Life style } \\
\hline Skip breakfast & & $1,087(14.8)$ & $427(39.3)$ \\
\hline Diet low in vegetables & & $1,261(17.2)$ & $608(48.2)$ \\
\hline Eat till full & & $3,535(48.3)$ & $832(23.5)$ \\
\hline Prefer oily foods & & $2,299(31.4)$ & $806(35.1)$ \\
\hline Prefer salty foods & & $3,187(43.5)$ & $942(29.6)$ \\
\hline Do not exercise regularly & & $4,302(58.8)$ & $966(22.5)$ \\
\hline Do not walk briskly & & $1,462(20.0)$ & $524(35.8)$ \\
\hline Smoke cigarettes & & $3,371(46.0)$ & $373(11.1)$ \\
\hline Drink alcoholic beverages regularly & & $5,603(76.5)$ & $241(4.3)$ \\
\hline \multicolumn{4}{|l|}{ Biological markes } \\
\hline Systolic blood pressure & $\geq 140 \mathrm{mmHg}$ & $1,012(13.8)$ & $267(26.4)$ \\
\hline Diastolic blood pressure & $\geq 90 \mathrm{mmHg}$ & $839(11.5)$ & $276(32.9)$ \\
\hline Total cholesterol & $\geq 220 \mathrm{mg} / \mathrm{dl}$ & $1,991(27.2)$ & $537(27.0)$ \\
\hline High density lipoprptein-cholesterol & $\leq 40 \mathrm{mg} / \mathrm{dl}$ & $1,491(20.4)$ & $522(35.0)$ \\
\hline Triglyceride & $\geq 200 \mathrm{mg} / \mathrm{dl}$ & $1,074(14.7)$ & $480(44.7)$ \\
\hline Fasting plasma glucose & $\geq 110 \mathrm{mg} / \mathrm{dl}$ & $1,184(16.2)$ & $432(36.5)$ \\
\hline Uric acid & $\geq 7.0 \mathrm{mg} / \mathrm{dl}$ & $921(12.6)$ & $360(39.1)$ \\
\hline Body mass index & $\geq 26 \mathrm{~kg} / \mathrm{m}^{2}$ & $838(11.5)$ & $155(18.5)$ \\
\hline
\end{tabular}

\section{Data Analysis}

The following were defined as abnormal biological markers in this study: systolic blood pressure (SBP) $\geq 140$ $\mathrm{mmHg}$, diastolic blood pressure (DBP) $\geq 90 \mathrm{mmHg}$, total cholesterol (TC) $\geq 220 \mathrm{mg} / \mathrm{dl}$, high-density lipoproteincholesterol (HDL-C) $<40 \mathrm{mg} / \mathrm{dl}$, triglyceride $(\mathrm{TG}) \geq 200$ $\mathrm{mg} / \mathrm{dl}$, fasting plasma glucose (FPG) $\geq 110 \mathrm{mg} / \mathrm{dl}$, uric acid (UA) $\geq 7.0 \mathrm{mg} / \mathrm{dl}$, and body mass index (BMI) $\geq 26$. Associations between favorably modified life-styles and improved biological markers after 3 years were assessed.

Differences in frequency were examined by the MantelHaenszel extension test adjusting for age, and odds ratio (OR) was routinely calculated with its $95 \%$ confidence interval (CI). When OR is greater (less) than 1, it implies that a favorably modified life-style is positively (negatively) associated with an improved biological marker. The strength of association is expressed as the size of the OR. Statistical significance of association is judged by the $95 \%$ $\mathrm{CI}$; that is, when the $95 \% \mathrm{CI}$ does not include 1, the association is statistically significant. Multiple logistic regression using dummy variables was also applied for the test of independent contribution of each favorably modified lifestyle. Statistical analyses were performed using an SAS package (version 6.0.8, SAS Institute, Cary, NC, USA). A p-value less than 0.05 (2-tailed) was considered statistically significant.

\section{Results}

\section{Frequency of Unfavorable Life-Style and} Abnormal Biological Markers

Table 1 shows the frequency of men who, among the 7,321 men, had had unfavorable life-styles and abnormal biological markers in 1989 and who had improved such life-styles in 1992. Unfavorable life-styles frequently observed were 'drink alcoholic beverages regularly' (76.5\%), 'do not exercise regularly' $(58.8 \%)$, 'eat till full' $(48.3 \%)$ and 'smoke cigarettes' $(43.5 \%)$. Those less frequently observed were 'skip breakfast' (14.8\%) and 'do not walk briskly' $(20.0 \%)$.

By $1992,48.2 \%$ of the study objects with a shortage of vegetables in the diet $(608 / 1261), 39.3 \%$ of those skipping breakfast (427/1087), 35.8\% of those not walking briskly (524/1462), and $35.1 \%$ of those preferring oily foods (806/2299) had improved their problematic life-styles. In contrast, only $4.3 \%$ of drinkers and $11.1 \%$ of smokers had abandoned their habits.

There was a wide range in the frequency of abnormal biological markers: from $11.5 \%$ of DBP and BMI to $27.2 \%$ of TC in 1989. Of them, improvements (ie, shift from abnormal to normal zone) were observed in BMI (from $18.5 \%)$ and TG (44.7\%) in 1992.

\section{Relationship Between Improved Life-Style and Normalized Biological Markers}

To examine the effects of a favorable life-style modification, we calculated the age-adjusted OR of improved lifestyles for normalized biological markers in the 3 years from 1989 to 1992 . The results are summarized in Table 2.

Twenty-four $(5.6 \%)$ out of 427 men who began to eat breakfast normalized their previously abnormal DBP, while only $17(2.6 \%)$ of the 660 who continued skipping breakfast normalized their DBP (adjusted OR 2.89; 95\% CI 1.29-6.46). This OR indicated that 'began to eat breakfast' was positively and significantly associated with normalized DBP with 2.89-fold likelihood. 'Began to eat breakfast' was also positively and significantly associated with a normalized TC (adjusted OR 1.84; 95\% CI 1.05-3.21). 'Increased vegetables intake' was significantly associated with a normalized DBP (adjusted OR 2.60; 95\% CI 1.18-5.75). Normalized BMI was found in $31(3.7 \%)$ among 832 men who stopped 'eating until full' and in 61 (2.3\%) among 2,703 men who continued to eat until full (adjusted OR 2.03; 95\% CI 1.25-3.28), indicating that BMI was significantly normalized when food intake was moderated, with approximately 2 -fold likelihood. 'Stop eating till full' were also significantly associated with a normalized UA (adjusted OR 1.65; 95\% CI 1.07-2.52) and TC (adjusted OR 1.43; 95\% CI 1.04-1.97). When the intake of salty foods was reduced, HDL-C was normalized with 1.46-fold likelihood (adjusted OR 1.46; 95\% CI 1.05-2.04). However, only 24 (2.5\%) out of 942 men who reduced their salty food intake normalized their SBP, whereas $82(3.7 \%)$ of 2,245 men who continued to eat salty foods achieved 
Table 2 Adjusted Odds Ratios Between Improvement of Unfavorable Life-Style and Normalization of abnormal Biological Markers From 1989 to 1992 Among 7,321 Male Participants

\begin{tabular}{|c|c|c|c|c|c|c|c|c|}
\hline & $S B P$ & $D B P$ & $T C$ & $H D L-C$ & $T G$ & $F P G$ & $U A$ & $B M I$ \\
\hline Began to eat breakfast & 1.91 & $2.89 *$ & $1.84 *$ & 0.79 & 1.23 & 0.96 & 1.41 & 1.17 \\
\hline Increased vegetable intake & 1.26 & $2.60 *$ & 0.85 & 1.22 & 1.17 & 1.34 & 1.04 & 2.46 \\
\hline Stopped eating till full & 1.00 & 1.34 & $1.43 *$ & 1.11 & 1.35 & 0.77 & $1.65 *$ & $2.03 * *$ \\
\hline Reduced oily foods & 1.03 & 1.01 & 1.11 & 1.15 & 0.97 & 1.22 & 1.42 & 1.60 \\
\hline Reduced salty foods & $0.53^{+}$ & 0.81 & 0.98 & $1.46^{*}$ & 0.93 & 0.89 & 1.29 & 1.20 \\
\hline Started exercise regularly & 0.79 & 0.96 & 1.07 & $1.69 * *$ & 1.09 & 0.93 & 1.39 & 1.38 \\
\hline Started walking briskly & 0.76 & 1.17 & $1.85 * *$ & 1.10 & 0.96 & 1.37 & 1.32 & 1.59 \\
\hline Quit smoking & 1.32 & 0.47 & 0.98 & $2.55 * * *$ & 1.03 & 1.18 & $0.41^{++}$ & 1.15 \\
\hline Quit drinking & 1.29 & 2.05 & 1.07 & 0.98 & 1.57 & 1.28 & 1.29 & 1.44 \\
\hline
\end{tabular}

Postive association $(O R>1) ; * p<0.05, * * p<0.01, * * * P<0.001$.

Negative association $(O R<1) ;{ }^{+} p<0.05,{ }^{++} p<0.01$.

Odds ratio is the ratio of 'normalized/non-normalized ratio of each laboratory test in the respective unimproved life style group' over 'normalized/non-normalized ratio in the correspondent improved life style group' after adjustment of age. SBP, systolic blood pressure; DBP, diastolic blood pressure; TC, total cholesterol; HDL-C, high-density lupoproten-cholestrol; TG, trghyeride; FPG, fasting plasma glucase; UA, uric acid; BMI, body mass index.

Table 3 Interrelationship in Improvement of Life-Style From 1989 to 1992 Among 7,321 Male Participants (Values are Odds Rations)

\begin{tabular}{|c|c|c|c|c|c|c|c|c|c|}
\hline & $\begin{array}{c}\text { Began to } \\
\text { eat } \\
\text { breakfast }\end{array}$ & $\begin{array}{l}\text { Increased } \\
\text { vegetable } \\
\text { intake }\end{array}$ & $\begin{array}{c}\text { Stopped } \\
\text { eating } \\
\text { till full }\end{array}$ & $\begin{array}{l}\text { Reduced } \\
\text { oily foods }\end{array}$ & $\begin{array}{c}\text { Reduced } \\
\text { salty foods }\end{array}$ & $\begin{array}{c}\text { Started } \\
\text { exercise } \\
\text { regularly }\end{array}$ & $\begin{array}{c}\text { Started } \\
\text { walking } \\
\text { briskly }\end{array}$ & $\begin{array}{c}\text { Quit } \\
\text { smoking }\end{array}$ & $\begin{array}{c}\text { Quit } \\
\text { drinking }\end{array}$ \\
\hline Began to eat breakfast & & $2.76 * * *$ & $1.63 *$ & 1.41 & $1.87 * *$ & 1.38 & 1.08 & 1.49 & 0.91 \\
\hline Increased vegetable intake & & & 1.16 & $1.64 *$ & $2.69 * * *$ & $1.66 * *$ & 1.16 & 1.15 & 1.46 \\
\hline Stopped eating till full & & & & $2.39 * * *$ & $1.72 * * *$ & $1.39 * *$ & 1.09 & 0.69 & $1.72 * *$ \\
\hline Reduced oily foods & & & & & $2.21 * * *$ & $1.40^{*}$ & 1.22 & 0.96 & 1.08 \\
\hline Reduced salty foods & & & & & & $1.28 *$ & 1.11 & 1.00 & 1.10 \\
\hline Started exercise regularly & & & & & & & $2.85 * * *$ & $1.77 * * *$ & 1.16 \\
\hline Started walking briskly & & & & & & & & 1.30 & 1.15 \\
\hline Quit smoking & & & & & & & & & 1.48 \\
\hline
\end{tabular}

$* p<0.05, * * p<0.01, * * * P<0.001$.

Odds ratio is the ratio of 'improved/non-improved ratio of each life style in the respective improved life style group' over 'improved/non-improved ratio in the correspondent unimproved life style group' after adjustment of age.

SBP normalization (adjusted OR 0.53; 95\% CI 0.32-0.89); indicating that sodium restriction was inversely and significantly associated with blood pressure normalization.

Ninety-two $(9.5 \%)$ out of 966 men who started exercising regularly normalized their HDL-C, while $229(6.7 \%)$ of 3,336 who remained sedentary achieved a normalized HDL-C (adjusted OR 1.69; 95\% CI 1.24-2.29). 'Began to walk briskly' was significantly associated in a positive fashion with a normalized TC (adjusted OR 1.85; 95\% CI 1.19-2.89). Forty-nine (13.1\%) out of 373 men who quit smoking normalized their HDL-C, while 238 (7.9\%) of 2,998 who continued to smoke had a normalized HDL-C (adjusted OR 2.55; 95\% CI 1.68-3.86). However, 'quit smoking' was inversely and significantly associated with UA normalization (adjusted OR $0.41 ; 95 \%$ CI $0.22-0.78$ ). 'Quit regular drinking' was not linked to any normalized biological markers with statistical significance.

A multivariate analysis by a logistic regression model did not essentially alter these associations between lifestyle modifications and improvements in the biological markers. But the OR of 'stopped eating till full' for UA normalization and of 'reduced salty food intake' for HDL$\mathrm{C}$ normalization turned to be insignificant, and the inverse association of 'quit smoking' with DBP normalization reached statistical significance (adjusted OR 0.40; 95\% CI 0.16-0.98).

We also examined the relationships between continued unfavorable life-style and no change/worsening of abnor- mal biological markers in the same population, as this was the contraposition of the aforementioned theme. From that we obtained results which almost reversed the earlier findings (data not shown).

\section{Interrelationship Among Life-Style Modifications}

Table 3 summarizes the adjusted OR for interrelationships among favorably modified life-styles.

Improved dietary habits were associated with each other. For example, 55 (56.7\%) out of 97 men who began to eat breakfast also increased their vegetable intake, whereas only $58(32.2 \%)$ of the 180 who continued to skip breakfast increased vegetable intake (adjusted OR 2.76; 95\% CI 1.67-4.56), indicating that when one began to eat breakfast, one also ate more vegetables, with a 2.76 -fold likelihood of statistical significance. 'Started exercising regularly' was also significantly linked to 'increased vegetable intake' (adjusted OR 1.66; 95\% CI 1.17-2.33) and such other dietary improvements as 'stopped eating till full,' 'reduced oily foods' and 'reduced salty foods'. Smoking ceased in $64(14.3 \%)$ out of 448 men who started exercising regularly, whereas it ceased in only $146(8.6 \%)$ of 1696 who remained sedentary (adjusted OR $1.77 ; 95 \%$ CI 1.30-2.42).

\section{Discussion}

This is the first study, to our best knowledge, which 
systematically examined associations between life-style and cardiovascular risk factors over a 3-year period in a large, male, working population. Because no special interventions other than routine verbal advice from the Center occurred, the life-style changes were presumed to be voluntary.

In this study, the focus was on the shift of the risk factors from the abnormal to the normal zone, not on changes in the within-normal range. All biological markers, originally continuous variables, were dichotomized and compared with qualitative changes in life-style.

Normalization of DBP was significantly associated with not-skipping breakfast and increased vegetable intake. Regular intake of breakfast is one of the seven so-called health practices? and Kenkel ${ }^{8}$ reported that this practice was weakly associated with BP in a positive fashion. Several investigators ${ }^{9-13}$ have shown that hypertension is less frequent in vegetarians. An increased vegetable intake may lead to increased serum potassium concentration ${ }^{12}$ and either reduced sympathoadrenal activities or increased atrial natriuretic peptide ${ }^{13}$ which would consequently result in lowering BP.

In contrast, dietary sodium restriction was significantly associated with an elevation of SBP in our study. According to the cross-center analysis of Intersalt, ${ }^{14,15}$ a direct association between sodium excretion and BP was not shown, and some genetic factors might determine agedependent BP increases beyond life-style modification. Gene analyses or randomized trials will therefore be required to disclose this particular aspect.

As expected, stopping eating till full decreased the serum TC abnormality. However, a reduction in oily food intake did not significantly improved a TC abnormality. This particular finding might possibly be explained as follows: to reduce the total energy intake means, in Japan, restricting saturated fatty acid-rich foods, and so reducing deep-fried dishes (representative oily foods in Japan and usually cooked with unsaturated fatty acid-rich vegetable oils) would not reduce the serum TC level16-18 Eating breakfast everyday was also associated with TC reduction. Although an association between the frequency of meals and lipid metabolism has only rarely been investigated 19 not taking meals regularly may lead to compensatory overintake at other meals, which would result in excess cholesterol synthesis.

Hypo-HDL-cholesterolemia was improved by starting regular exercise, a well known association, ${ }^{20-26}$ and the American College of Sports Science, American Heart Association and The Center for Disease Control and Prevention have recommended daily sports activities. ${ }^{27-29}$ In our study, however, brisk walking did not significantly improve the serum HDL-C abnormality, which might be explained in part by the low exercise intensity of walking even when one walks briskly $3^{0}$ It would imply that rather more strenuous exercise might be needed to increase the HDL-C level. Smoking cessation was associated with a favorable shift of HDL-C to normal values. The mechanism of this effect has not been thoroughly elucidated. Because quitting smokeless tobacco did not increase HDL$\mathrm{C}$, 1 this change in lipid metabolism might be affected by something other than nicotine.

TG was not significantly affected by life-style modifications in this study, possibly because of the large intraindividual variation of this marker. We also found no significant associations between FPG and favorable life-style modifications. FPG is not a sensitive marker of impaired glucose tolerance, as compared to the serum insulin level, so changing dietary habits and physical activities would not accompany an FPG shift across $110 \mathrm{mg} / \mathrm{dl}$.

Uricemic status was rather worsened after quitting smoking. Increased eating after quitting smoking might have some effect on the status, because quitting smoking and stopping eating till full were somewhat negatively interrelated. However, multiple logistic regression analysis did not diminish the inverse association between smoking cessation and UA normalization, so the true mechanism remains uncertain. In this study BMI was not affected by quitting smoking. Physical activity, which might accompany alcohol abstinence, would cancel out the unfavorable effects on BMI of quitting smoking? 2

This study has some limitations. First, many examinees had undergone previous health check-ups. Some of them might have already tried to modify their life-style, which would possibly attenuate the associations between a favorably modified life-style and improved biological markers, resulting in underestimated effects. Second, we failed to exclude participants who took medication because of incomplete information in the questionnaire regarding drugs. However, in this center drug therapy is recommended only for participants with marked abnormalities, so changes in the variables of drug-users across the cut-off levels set for the study seem less likely than those of nondrug-users. Third, the questionnaire did not cover all aspects of the life-style, so it is unknown how variables such as resting, sleeping, and mental or social activities could change risk factor profiles.

Despite those limitations, we demonstrated that certain favorable life-style modifications could significantly attenuate abnormal biological risk factors for cardiovascular diseases. Thus, appropriate advice on life-style habits should be given to each examinee in a positive, systematic way following the periodic health check-ups in order to reduce the person's risk.

\section{Acknowledgments}

This study was supported in part by the Research Grant for Cardiovascular Diseases (5C-5) from the Ministry of Health and Welfare. We thank the technical staff of Aichi Prefectural Center of Health Care for their generous assistance in collecting data for this study.

\section{References}

1. Kannel WB, Belanger A, D’Agostino R, Israel I: Physical activity and physical demand on the job and risk of cardiovascular disease and death: the Framingham Study. Am Heart J 1986; 112: 820-825

2. Cupples ME, McKnight A: Randomized controlled trial of health promotion in general practice for patients at high cardiovascular risk. BMJ 1994; 309: $993-996$

3. Haskell WL, Alderman EL, Fair JM, Maron DJ, Mackey SF, Superko HR, et al: Effects of intensive multiple risk factor reduction on coronary atherosclerosis and clinical cardiac events in men and women with coronary artery disease: The Stanford Coronary Risk Intervention Project (SCRIP). Circulation 1994; 89: 975-990

4. Kannel WB, Wilson P, Blair SN: Epidemiological assessment of the role of physical activity and fitness in development of cardiovascular disease. Am Heart J 1985; 109: 876-885

5. Eichner ER: Exercise and heart disease: Epidemiology of the "exercise hypotheses'. Am J Med 1983; 75: 1008-1023

6. Japan Industrial Safety and Health Association. Industrial Safety and Health Law and related registration of Japan. Tokyo: Japan Industrial Safety and Health Association, 1991

7. Belloc NB, Breslow L: Relationship of physical health status and health practices. Prev Med 1972; 1: 409-421

8. Kenkel DS: Should you eat breakfast? Estimates from health production functions. Health Econ 1995; 4: 15-29

9. Singh RB, Rastogi SS, Singh R, Ghosh S, Niaz MA: Effects of guava 
intake on serum total and high-density lipoprotein cholesterol levels and on systemic blood pressure. Am J Cardiol 1992; 70: 1287-1291

10. Sciarrone SE, Strahan MT, Beilin LJ, Burke V, Rogers P, Rouse IL: Biochemical and neurohormonal responses to the introduction of a lacto-ovovegetarian diet. J Hypertens 1993; 11: 849-860

11. Singh RB, Niaz MA, Ghosh S: Effect on central obesity and associated disturbances of low-energy, fruit- and vegetable-enriched prudent diet in north Indians. Postgrad Med J 1994; 70: 895-900

12. Singh RB, Ghosh S, Singh R: Effects on serum lipids of adding fruits and vegetables to the prudent diet in the Indian Experiment of Infarct Survival (IEIS). Cardiology 1992; 80: 283-293

13. Sciarrone SE, Strahan MT, Beilin LJ, Burke V, Rogers P, Rouse IR: Ambulatory blood pressure and heart rate responses to vegetarian meals. J Hypertens 1993; 11: 277-285

14. Elliott and Intersalt Cooperative Research Group: Intersalt: an international study of electrolyte excretion and blood pressure. Results for 24 hour urinary sodium and potassium excretion. BMJ 1988; 297: 319-328

15. Elliott P, Marmot M, Dyer A, Joossens J, Kesteloot H, Stamler R, et al: The INTERSALT study: main results, conclusions and some implications. Clin Exp Hyperthens A 1989; A11: 1025-1034

16. Mensink RP, Katan MB: Effect of dietary fatty acids on serum lipids and lipoproteins: A meta-analysis of 27 trials. Arterioscler Thromb 1992; 12: $911-919$

17. Dietschy JM: Dietary fatty acids and the regulation of plasma low density lipoprotein cholesterol concentrations. J Nutr 1998; 128: $444 \mathrm{~S}-448 \mathrm{~S}$

18. Nagata T, Nakaya K, Takahashi A, Yoshida I, Okamoto Y: Relationship between serum saturated fatty acids and serum total cholesterol and HDL-cholesterol in humans. Ann Clin Biochem 1994; 31: 240-244

19. Jenkins DJ, Wolever TM, Vuksan V, Brighenti F, Cunnane SC, Rao $\mathrm{AV}$, et al: Nibbling versus gorging: metabolic advantages of increased meal frequency. N Engl J Med 1989; 321: 929-934

20. Adamopoulos PN, Macrilakis K, Papamichael C, Malakos I, Panayidis N, Moulopoulos SD: Physical activity and relationship with coronary heart disease risk factors. Acta Cardiol 1993; 48: $523-534$

21. Hubinger LM, Mackinnon LT: The acute effect of $30 \mathrm{~min}$ of moderate exercise on high density lipoprotein cholesterol in untrained middle-aged men. Eur J Appl Physiol 1992; 65: 555-560

22. Kokkinos PF, Holland JC, Narayan P, Colleran JA, Dotson CO, Papademetriou V: Miles run per week and high-density lipoprotein cholesterol levels in healthy, middle-aged men: A dose-response relationship. Arch Intern Med 1995; 155: 415-420

23. Suter E, Marti B, Gutzwiller F: Jogging or walking: comparison of health effects. Ann Epidemiol 1994; 4: 375-381

24. Serrat-Serrat J, Ordonez-Llanos J, Serra-Grima R, Gomez-Gerique JA, Pellicer-Thoma E, Payes-Romero A, et al: Marathon runners presented lower serum cholesteryl ester transfer activity than sedentary subjects. Atherosclerosis 1993; 101: 43-49

25. Pay HE, Hardman AE, Jones GJ, Hudson A: The acute effects of low-intensity exercise on plasma lipids in endurance-trained and untrained young adults. Eur J Appl Physiol 1992; 64: 182-186

26. King AC, Haskell WL, Young DR, Oka RK, Stefanick ML: Longterm effects of varying intensities and formats of physical activity on participation rates, fitness, and lipoproteins in men and women aged 50-65 years. Circulation 1995; 91: 2596-2604

27. American College of Sports Medicine. Guidelines for graded exercise testing and exercise prescription, 3rd edn. Philadelphia: Lea and Febiger, 1986

28. Fletcher GF, Balady G, Froelicher VF, Hartley LH, Haskell WL, Pollock ML: Exercise standards: A statement for health care professionals from the American Heart Association. Writing Group. Circulation 1995; 91: 580-615

29. Pate RR, Pratt M, Blair SN, Haskell WL, Macera CA, Bouchard C, et al: Physical activity and public health: A recommendation from the Centers for Disease Control and Prevention and the American College of Sports Medicine. JAMA 1995; 273: 402-407

30. Stein RA, Michielli DW, Glantz MD, Sardy H, Cohen A, Goldberg $\mathrm{N}$, et al: Effects of different exercise training intensities on lipoprotein cholesterol fractions in healthy middle-aged men. Am Heart $J$ 1990; 119: $277-283$

31. Allen SS, Hatsukami D, Jensen J, Grillo M, Bliss R: Effects of treatment on cardiovascular risk among smokeless tobacco users. Prev Med 1995; 24: 357-362

32. Gordon T, Kannel WB: Drinking and its relation to smoking, BP, blood lipids, and uric acid: The Framingham study. Arch Intern Med 1983; 143: $1366-1374$ 